\title{
PREVISÃo DA DEMANDA POR ENERGIA ELÉTRICA PARA CLASSES DE CONSUMO NA REGIÃO NORDESTE, USANDO OLS DINÂMICO E MUDANÇA DE REGIME
}

\author{
Guilherme Irffi ${ }^{\S}$ \\ Ivan Castelar \\ Marcelo Lettieri Siqueira ${ }^{\dagger}$ \\ Fabrício Carneiro Linhares
}

\begin{abstract}
RESUMO
Este artigo se propõe a estimar a demanda por energia elétrica para as classes residencial, comercial e industrial na região Nordeste do Brasil, no período de 1970 a 2003, utilizando DOLS e Mudança de Regime. A partir dos vetores de cointegração são estimados os Modelos de Correções de Erros, os quais fornecem a base para se fazer previsões para o período de 2004 a 2010. A partir dos resultados apresentados por este estudo, são feitas comparações das elasticidades-preço e renda de curto e longo prazo com aquelas obtidas por outros estudos feitos para o Brasil, bem como com as previsões feitas pela Eletrobrás e por Siqueira, Cordeiro Jr. e Castelar (2006). As metodologias utilizadas nesse estudo apresentam previsões mais precisas do que os demais estudos para o período 2004/06.
\end{abstract}

Palavras-chave: Modelos de Previsão, demanda por energia elétrica, DOLS, Mudança de Regime, Nordeste do Brasil.

\begin{abstract}
The objective of this research is to estimate the residential, commercial and industrial demand for electric energy in the Northeast of Brazil during the period 1970-2003. Two different methodologies were used to compute price and income elasticities of demand: i) DOLS, proposed by Stock and Watson (1993); and ii) Regime Switching, by Gregory and Hansen (1996). Error Correction Models were estimated using the cointegrating vectors. These models are used to perform long-run forecasts of demand for the period 2004-2010. The main results are then compared to those from other studies about Brazilian's price and income elasticities of demand for electric energy. Furthermore, an analysis of forecast performance shows that these models predict as good or better than Eletrobrás and Siqueira, Cordeiro Jr. e Castelar (2006).
\end{abstract}

Keywords: Forecasting Models, Demand for Electric Energy, DOLS, Regime Switch, Northeast of Brazil.

JEL classification: C22, C53, Q41.

$\S$ Doutorando em Economia (CAEN/UFC). Professor da Universidade Federal do Ceará, Dep. Economia, Campus Sobral. Endereço para contato: Praça Senador Figueira, Rua Anahid Andrade, S/N, Centro, Sobral, CE - Brasil. E-mail: guidirffi@gmail.com.

a Doutor em Economia pela University of Florida, U.F. USA. Professor do Departamento de Economia Aplicada da UFC. E-mail: lume1250@yahoo.com.br.

$\dagger$ Doutor em Economia pela Universidade Federal de Pernambuco (PIMES/UFPE), Brasil. Pesquisador do CAEN/UFC. E-mail: lettieri@caen.ufc.br.

† Doutor em Economia pela University of New Hampshire, UNH, USA. Professor do CAEN/UFC. E-mail: flinhares@ caen.ufc.br.

Endereço para contato: Av. da Universidade, 2700 - Benfica - Fortaleza - CE - Brasil. CEP: 60020-181.

Recebido em novembro de 2007. Aceito para publicação em setembro de 2008. 


\section{INTRODUÇÃO}

O Brasil experimentou um período de prosperidade no setor energético durante as décadas de 50, 60 e 70, do século XX, em virtude de investimentos expressivos em infraestrutura. Naquelas décadas, a geração e a produção de energia elétrica desenvolveram-se rapidamente a custos relativamente baixos e com significativo progresso tecnológico no setor.

Na segunda metade da década de 1950, destacam-se três pontos principais do Plano de Metas do governo Kubitschek. O primeiro foi o investimento estatal em infraestrutura com destaque para os setores de transporte e energia elétrica. O segundo contemplou o estímulo ao aumento da produção de bens intermediários, e, por fim, os incentivos à introdução dos setores de bens duráveis e de capital. Em particular, o setor elétrico foi bastante privilegiado, dado o objetivo de ampliar a capacidade de produção do País. Tal expansão foi possível graças à facilidade de obtenção de recursos financeiros internacionais e pela disponibilidade dos recursos hidrelétricos próximos aos mercados consumidores, o que permitiu incrementos de escala no setor.

A partir da criação da Eletrobrás no começo dos anos de 1960, responsável pela consolidação e integração do setor elétrico nacional, o potencial hidrelétrico brasileiro foi mais bem aproveitado com a conexão dos mercados produtor, distribuidor e consumidor. O resultado foi a expansão no consumo de energia elétrica ao longo dos anos de 1960, 1970 e 1980 em virtude do aumento da capacidade geradora das hidrelétricas, bem como pela expansão da distribuição em todo o território brasileiro.

Por outro lado, o setor energético demonstrou sinais de crise, no período de 1980 a 2000 , devido à perda da capacidade de financiamento dos investimentos estatais, os quais eram necessários para sua expansão, e pelo fraco desempenho econômico do País.

No entanto, a crise não se agravou durante os anos de 1980 graças à tensão pela qual passava o setor petrolífero. Além desses fatores, uma forte recessão assolou o País e o setor operou aquém da sua capacidade. Desta maneira, o setor energético administrou satisfatoriamente a retomada do crescimento experimentado pela economia brasileira a partir de 1994. Mais uma vez, devido à falta de investimento no setor elétrico, a década de 1990 foi um período de baixo crescimento da oferta de energia.

Em 1995, o setor elétrico brasileiro passou por uma reformulação, caracterizado pela abertura dos mercados, eliminação de monopólios e retirada do Estado de funções típicas de empreendedor, propiciando oportunidades de investimento para o setor privado.

Durante os anos 2001 e 2002, a região Nordeste do Brasil juntamente com as regiões Sudeste, Centro-Oeste e os Estados de Tocantins e Pará experimentaram um racionamento na demanda, quando o governo impôs, com base na resolução n. 4, de 22/05/2004, um sistema de quotas, sobretarifas e bônus para os consumidores que ultrapassassem ou cumprissem determinadas metas de consumo energético. 
Diante desse cenário pós-racionamento, verifica-se que um dos problemas mais evidentes enfrentado pelo setor elétrico é o descompasso entre a expansão da oferta e as previsões de demanda, de médio e longo prazo.

Para que a oferta possa ser ajustada às necessidades do mercado, é vital quantificar com maior precisão a trajetória de expansão da demanda. A necessidade desse ajuste motiva, portanto, este estudo a ter como objetivo projetar a demanda por energia elétrica a partir das elasticidades-preço e renda para as classes residencial, comercial e industrial da região Nordeste do Brasil, no período de 2004-2010, com o intuito de contribuir para um melhor planejamento do setor elétrico.

A base de dados utilizada neste estudo é aquela construída por Siqueira, Cordeiro Jr. e Castelar (2006), doravante denominado SCC (2006). O que diferencia este estudo daquele é a metodologia escolhida para obter os vetores de cointegração, já que, em SCC (2006), foram usados modelos autorregressivos com correção de erros (VAR/VEC), estimados por OLS; enquanto que, no presente trabalho, tais vetores serão estimados pelas técnicas desenvolvidas por Stock e Watson (1993) e por Gregory e Hansen (1996), conhecidas respectivamente como OLS Dinâmico (DOLS) e Mudança de Regime.

Assim, a principal contribuição desta pesquisa está relacionada à utilização de uma metodologia alternativa, vis-à-vis àquela encontrada em SCC (2006), para a estimação dos Modelos Vetoriais Autorregressivos (VEC). Posteriormente, com base nesses modelos, serão geradas previsões da demanda por energia elétrica para as classes residencial, comercial e industrial da região Nordeste do Brasil no período de 2004 a 2010.

Este artigo apresenta, além desta introdução, mais cinco seções. A segunda traz uma revisão de literatura empírica nacional e internacional. O modelo teórico, a base de dados, as metodologias e os cenários para previsão são discutidos na terceira seção. Em seguida, destacam-se os resultados dos testes da raiz unitária e cointegração, a estimação do vetor de cointegração por DOLS e Mudança de Regime, e o VEC, e, posteriormente, faz-se uma discussão das elasticidades-preço e renda de curto e longo prazo por meio da análise comparativa com demais estudos para a região Nordeste e para o Brasil. A quinta seção contém os resultados das previsões para o período de 2004-2010, geradas a partir do VEC. Em seguida, são apresentadas as considerações finais.

\section{REVISÃO DA LITERATURA}

Alguns estudos foram realizados sobre a demanda por energia elétrica no Brasil durante as três últimas décadas. Isso torna este trabalho uma atualização da literatura nacional devido à utilização de metodologias econométricas distintas dos trabalhos realizados anteriormente.

Modiano (1984) foi um dos primeiros a mensurar as elasticidades-renda e preço da energia elétrica para as classes residencial, comercial e industrial no período de 1963 a 1981 para o 
Brasil. Elas foram estimadas pelo método de mínimos quadrados com correção para correlação serial pelo método de Corchranne-Orcutt. Observa-se neste trabalho que somente as elasticidades-renda de longo prazo mostraram-se elásticas em relação à demanda por energia elétrica. Dessa forma, os resultados para as três classes são, respectivamente, (1.130), (1.019) e (1.181).

O trabalho desenvolvido por Andrade e Lobão (1997) é, em certa medida, uma extensão do estudo de Modiano (1984). Nele, foi elaborada uma análise da evolução do consumo residencial de energia elétrica para o Brasil, no período 1963 a 1995, através da estimação das elasticidades-renda e preço da demanda agregada para capturar o efeito direto. As elasticidadespreço e renda de curto prazo são superiores às de longo prazo, (-0.060) e (-0.051), e (0.212) e (0.210), respectivamente. Já para capturar o efeito indireto, os autores utilizaram o preço dos eletrodomésticos. A estimação foi feita por modelagem de um vetor autorregressivo (VAR) sob a representação de um VEC.

É possível destacar, ainda, o estudo de Schmidt e Lima (2004) que estimou as elasticidades-preço e renda de longo prazo por cointegração para a demanda por energia elétrica para as classes residencial, comercial e industrial. Tais autores obtiveram resultados para a elasticidaderenda superior a um, enquanto a elasticidade-preço é inferior à unidade, em módulo. Além disso, foram feitas previsões para o consumo de energia elétrica no período de 2001 a 2005.

Devido à crise do racionamento nos anos de 2001 e 2002, SCC (2006) propuseram uma metodologia para incorporar os efeitos desse racionamento nas previsões de demanda por energia elétrica ${ }^{1}$ para as classes de consumo residencial, comercial e industrial, utilizando como espaço de análise a região Nordeste.

As estimações feitas para as elasticidades-preço e renda de longo prazo foram calculadas pelos métodos de OLS, Mínimos Quadrados em Dois Estágios (MQ2E) e Modelos Vetoriais Autorregressivos (VAR/VEC). A elasticidade-renda de longo prazo mostrou-se maior na classe residencial do que nas classes comercial e industrial. Já as elasticidades-preço e renda de longo prazo são superiores às de curto prazo para as três classes.

Na última década, alguns estudos sobre a demanda por energia em países como China, Austrália, Jordânia, França e Grécia vêm utilizando a metodologia desenvolvida por Stock e Watson (1993), DOLS, a qual gera estimadores mais robustos para pequenas amostras, além de corrigir o viés, a simultaneidade e a correlação serial.

Assim, na busca por estimativas mais robustas para as elasticidades de longo prazo da demanda de carvão na China, Masih e Masih (1996) utilizaram tal metodologia em função da qualidade dos estimadores obtidos por DOLS ser superior a de outros métodos quando se dispõe de pequenas amostras. O estudo compreendeu o período de 1953 a 1992, no qual o consumo de carvão é explicado pelo preço real do carvão e pela renda real (PNB). O estudo conclui que as elasticidades-preço e renda de curto prazo são inferiores, em valor absoluto, às de longo prazo.

1 Foi adotada a hipótese de que o consumo converge assintoticamente para sua tendência de longo prazo. 
A função demanda por energia elétrica para a Jordânia utilizada por Al-Azzam e Hawdon (1999), durante o período de 1968-97, estimada por DOLS, é função da renda, da atividade de construção e da instabilidade política. Essas variáveis apresentaram um impacto significativo no consumo de energia elétrica. De todo modo, o preço real tem um efeito neutro ou fraco. Os autores argumentam que a variável que mensura a atividade de construção é uma indicação plausível do processo de desenvolvimento que envolve urbanização, além de possuir um impacto significativo em outras atividades nas quais também se faz uso de energia.

Por sua vez, Saed (2004) estimou a demanda total de energia para a Jordânia no período de 1980-1999, chegando à conclusão de que o crescimento econômico é acompanhado por um aumento proporcional no consumo de energia, pois a elasticidade-renda encontrada foi de (1.15). Verificaram, ainda, que o consumo de energia é negativamente correlacionado com o preço.

Já Akmal e Stern (2001) mensuraram as elasticidades de longo prazo para a demanda por eletricidade, gás natural e outros combustíveis para a Austrália, a partir do terceiro trimestre de 1969-70 ao segundo trimestre de 1998-9, por DOLS. A função demanda estimada por esses autores depende do preço do i-ésimo combustível, do preço dos combustíveis substitutos, do preço dos bens complementares e da renda.

Silk e Joutz (1997) investigaram os efeitos de variáveis econômicas no uso de energia empregando técnicas de cointegração, a qual permite desenvolver uma análise de curto e longo prazo através do VEC, com dados anuais para a demanda de eletricidade residencial dos EUA. Mais do que isso, os autores construíram um índice para o estoque de equipamentos elétricos e estimaram o modelo para os anos de 1949 a 1993. Os resultados sugeriram uma mudança de regime no consumo durante a década de 1960, e estes autores projetaram, ainda, a demanda para 1994 e 1995.

Em um estudo empírico para o Chipre, voltado para o consumo de energia elétrica residencial e do setor de serviços, Zachariadis e Pashourtidou (2007) aplicaram testes de raiz unitária com e sem quebra estrutural em nível, teste de cointegração, VEC, teste de causalidade de Granger e função impulso-resposta. Nesse estudo, os resultados mostraram que o setor comercial é menos elástico e reverte mais rápido para o equilíbrio do que o setor residencial.

\section{MODELO TEÓRICO E METODOLOGIA ECONOMÉTRICA}

Nesta seção serão apresentados o modelo teórico e a base de dados utilizados para a realização deste estudo, bem como os procedimentos econométricos adotados.

\subsection{Modelo teórico e a base de dados}

O modelo usado nesta análise é postulado pela teoria econômica para estimar a função demanda por energia elétrica, e está fundamentado nas seguintes hipóteses:

a. Não existe problema de demanda reprimida e a oferta de energia é infinitamente 
elástica, ou seja, a quantidade de energia demandada por cada classe de consumo é efetivamente ofertada. Logo, a quantidade consumida é uma proxy satisfatória para a quantidade demandada.

b. A demanda é influenciada pela tarifa média da classe, pela renda per capita (classe residencial) ou pelo produto do setor (classes comercial e industrial), pelo estoque de aparelhos elétricos e pelo preço de um bem substituto (setor industrial). A demanda foi modelada pela seguinte função não-linear:

$C_{t}=K_{1} T^{\alpha}{ }_{t} Y^{\beta}{ }_{t} E_{t}^{\gamma} P C^{\delta}{ }_{t}$

Sendo $\mathrm{C}_{\mathrm{t}}$ o consumo de energia elétrica no tempo $t ; K_{1}$ o consumo de subsistência (autônomo), $T_{t}$ é a tarifa média de energia elétrica da classe no tempo $t$; $Y_{t}$ é a renda familiar no tempo $t$ (para a classe residencial) ou o PIB do setor (classe comercial e industrial); $E_{t}$ é o estoque de aparelhos elétricos no tempo $t ; P C_{t}$ é o preço dos bens substitutos da classe de consumo no tempo $t$.

c. Supõe-se, também, que o estoque de aparelhos elétricos $\left(E_{t}\right)$ reaja positivamente aos aumentos na renda familiar ou no produto do setor $\left(Y_{t}\right)$ e negativamente aos aumentos nos preços dos aparelhos elétricos $\left(P E_{t}\right)$, e que estas variáveis se relacionem de acordo com a seguinte função:

$E_{t}=K_{2} P E^{\mu}{ }_{t} Y_{t}^{\theta}$

O sistema de equações composto por (1) e (2) poderia ser estimado pelo método de equações simultâneas. No entanto, SCC (2006) argumentam que não é possível encontrar uma proxy adequada para o estoque de equipamentos elétricos; logo, optaram por transformar (1) e (2) em uma única equação.

Substituindo (2) em (1) e aplicando logaritmo neperiano (ln) na equação resultante, temse a equação linear para a demanda por energia elétrica, expressa da seguinte maneira,

$$
\ln \left(C_{t}\right)=\varphi_{1}+\varphi_{2} \ln \left(T_{t}\right)+\varphi_{3} \ln \left(Y_{t}\right)+\varphi_{4} \ln \left(P E_{t}\right)+\varphi_{5} \ln \left(P C_{t}\right)
$$

Sendo

$$
\varphi_{1}=\ln \left(K_{1} K_{2}^{\gamma}\right), \varphi_{2}=\alpha ; \varphi_{3}=\beta+\theta \gamma ; \varphi_{4}=\gamma \cdot \mu ; \mathrm{e} \varphi_{5}=\delta,
$$

os coeficientes $\varphi_{2}, \phi_{3}, \phi_{4}$ e $\phi_{5}$ representam as elasticidades da demanda por energia elétrica em relação à tarifa média da classe, à renda familiar ou ao PIB do setor, ao preço de máquinas e equipamentos elétricos e ao preço de combustíveis (bem substituto para a classe industrial).

Espera-se que um aumento no nível real das tarifas e dos preços de equipamentos elétricos tenha um impacto negativo sobre o consumo, enquanto que, para o nível de renda, uma variável importante em qualquer análise sobre demanda, é de se esperar que um acréscimo resulte num aumento do consumo. Além destas variáveis, o modelo industrial ainda traz o nível de 
preço dos combustíveis, que são bens substitutos da energia elétrica, e cujo impacto na demanda espera-se, a priori, que seja positivo.

Em suma, uma relação negativa é esperada entre a tarifa e o preço de equipamentos elétricos e a demanda na relação de cointegração; por sua vez, uma relação positiva é esperada entre a renda e a demanda na relação de cointegração, assim como o preço dos combustíveis.

Para estimar a equação (3), utiliza-se a base de dados de SCC (2006), a qual é formada por dados anuais que se estendem pelo período de 1970 a 2003. Descrições mais detalhadas das variáveis e proxies utilizadas, bem como suas respectivas unidades de medidas e fontes, são apresentadas nos Quadros 1 a 3.

\section{Quadro 1 - Identificação das variáveis do modelo residencial}

\begin{tabular}{|lllll|}
\hline Sigla & Variável & Proxy Utilizada & Fontes & Unidade \\
\hline $\mathrm{Cr}$ & Demanda Residencial Média & Consumo Residencial/ População do NE & Chesf e IBGE & Kwh/hab. \\
$\mathrm{Tr}$ & Tarifa da Classe Residencial & Tarifa Média Residencial Nacional $\left(^{*}\right)$ & IPEA/Eletrobrás & $\mathrm{R} \$ / \mathrm{Mwh}$ \\
$\mathrm{PER}$ & Preço de Eletrodomésticos & IPA-OG-Eletrodomésticos & FGV/IPA & Índice \\
Yp & Renda per capita do NE & PIB per capita do NE $\left(^{*}\right)$ & SUDENE/Boletim & R $\$ /$ hab. \\
\hline
\end{tabular}

Fonte: Siqueira, Cordeiro Jr. e Castelar 2006. (*) Série deflacionada pelo IGP-DI (FGV) base dez 2002.

\section{Quadro 2 - Identificação das variáveis do modelo comercial}

\begin{tabular}{|c|c|c|c|c|}
\hline Sigla & Variável & Proxy Utilizada & Fontes & Unidade \\
\hline $\mathrm{Cc}$ & Demanda Comercial & Consumo Comercial & Chesf e IBGE & Mwh \\
\hline $\mathrm{Tc}$ & Tarifa da Classe Comercial & Tarifa Média Comercial Nacional (*) & IPEA/Eletrobrás & $\mathrm{R} \$ / \mathrm{Mwh}$ \\
\hline PEC & $\begin{array}{l}\text { Preço de Equipamentos } \\
\text { Elétricos do Setor Comercial }\end{array}$ & IPA- OG - Material Elétrico Total (*) & FGV/IPA & Índice \\
\hline Yc & Renda do setor Comercial do NE & PIB do NE - Serviços (*) & $\begin{array}{l}\text { SUDENE/Boletim } \\
\text { Conjuntural }\end{array}$ & Milhões de $\mathrm{R} \$$ \\
\hline
\end{tabular}

Fonte: Siqueira, Cordeiro Jr. e Castelar 2006. (*) Série deflacionada pelo IGP-DI (FGV) base dez 2002.

\section{Quadro 3 - Identificação das variáveis do modelo industrial}

\begin{tabular}{|lllll|}
\hline Sigla & Variável & Proxy Utilizada & Fontes & Unidade \\
\hline $\mathrm{Ci}$ & Demanda Industrial & Consumo Industrial & Chesf & Mwh \\
$\mathrm{Ti}$ & Tarifa da Classe Industrial & Tarifa Média Industrial Nacional $\left(^{*}\right)$ & IPEA/Eletrobrás & $\mathrm{R} \$ /$ Mwh \\
& Preço de Máquinas e Equipamentos & IPA-OG - Máquinas e Equipamentos & & Índice \\
$\mathrm{PEI}$ & Elétricos da Indústria & Industriais & FGV/IPA & SUDENE/Boletim de \\
Yi & Renda do Setor Industrial do NE & PIB Industrial do NE $\left(^{*}\right)$ & Conjuntural & R $\$$ \\
PC & Preço de Bens Substitutos & IPA-OG - Combustíveis e Lubrificantes & FGV/IPA & Índice \\
\hline
\end{tabular}

Fonte: Siqueira, Cordeiro Jr. e Castelar 2006. (*) Série deflacionada pelo IGP-DI (FGV) base dez 2002. 


\subsection{Metodologia econométrica}

Assim como os demais modelos que fazem uso de dados temporais, é importante descrever por meio de uma estrutura dinâmica a relação de equilíbrio de longo prazo presente no modelo. Por isso, a modelagem desenvolvida por Sims (1980) é utilizada em vários estudos dessa natureza, a qual recorre à técnica de vetores autorregressivos (VAR).

\subsubsection{Estimação da relação de equilíbrio de longo prazo: Stock e Watson - DOLS}

Na década passada, surgiu uma nova metodologia econométrica que provém de estimadores robustos em pequenas amostras para séries cointegradas. Esta metodologia ficou conhecida como Mínimos Quadrados Ordinários Dinâmicos, DOLS, desenvolvida por Stock e Watson (1993).

Tal metodologia apresenta evidências, baseadas em simulações de Monte Carlo, de que os estimadores são mais robustos em pequenas amostras quando comparados com outros estimadores alternativos. ${ }^{2}$ Mais do que isso, o DOLS é uma técnica para se obter estimadores eficientes para os vetores de cointegração que incluam componentes determinísticos e acomodem indistintamente variáveis de alta ordem de integração, de ordens distintas, cointegradas, bem como a possível simultaneidade entre as variáveis de um sistema de demandas (STOCK; WATSON, 1993).

No caso de as variáveis serem integradas de ordem um; ou seja, não-estacionárias, regressa-se uma variável em nível contemporâneo na outra variável e nos lags e leads da sua primeira diferença e um termo constante.

De acordo com Stock e Watson (1993), a presença de leads e lags de diferentes variáveis na equação de estimação, a qual possui um vetor cointegrante, elimina o viés de simultaneidade, bem como o viés de pequenas amostras.

A equação (4) descreve a demanda por energia elétrica que será estimada por DOLS,

$$
C_{t}=X_{t} M_{t}^{\top}+\sum_{i=-m}^{i=m} \varphi_{i} \Delta T_{t-i}+\sum_{i=-n}^{i=n} \rho_{i} \Delta Y_{t-i}+\sum_{i=-l}^{i=l} \phi_{i} P E_{t-i}+\sum_{i=-p}^{i=p} \vartheta_{i} \Delta P C_{t-i}
$$

Sendo $C$ o consumo; $T$, a tarifa da classe; $Y$, a renda (ou produto); $P E$, o preço de eletrodomésticos (classe residencial) ou preço de máquinas e equipamentos elétricos (classes comercial e industrial); $P C$ é o preço dos combustíveis, $M=[c, \alpha, \beta, \gamma, \lambda], X=\left[1, P_{t}, Y_{t}, P E_{t}, P C_{t}\right]$, e $m, n, l$ e $p$ são os leads, e $(-m),(-n),(-l)$ e $(-p)$, os lags dos regressores.

O estimador obtido por DOLS conta também com um mecanismo para corrigir correlação serial e endogeneidade e é, ainda, assintoticamente equivalente ao estimador de Máxima Verossimilhança [CHOI e OH (2003)].

2 Comparando com MQO, MQ2E, VAR/VEC. 
Logo, a estimação dos vetores cointegrantes por DOLS será utilizada neste trabalho para que se tenham estimadores mais robustos para pequenas amostras e, a partir dos resultados encontrados, serão realizadas comparações com as estimativas elaboradas por outros pesquisadores que utilizaram os métodos de OLS, MQ2E e VAR/VEC. Posteriormente, serão estimados os modelos VEC, os quais servirão de base para se fazer previsões de 2004-2010.

\subsubsection{Relação de longo prazo com mudança de regime}

Este estudo estima também a relação de longo prazo com uma mudança de regime, ou seja, um modelo no qual será capturada uma mudança de intercepto, caso ela exista, como descrito por Gregory e Hansen (1996). Este procedimento é uma extensão do teste de cointegração de Engle e Granger (1987).

O período em que ocorreu a mudança de regime é determinado de forma endógena. Logo, o período no qual houve uma mudança significativa na relação de longo de prazo entre as variáveis é determinado dentro do sistema.

A relação de cointegração é estimada por OLS, e o teste da raiz unitária é aplicado na regressão do erro. Além disso, adotou-se como sugestão para a data na qual ocorre a mudança de regime o teste $Z_{t}{ }^{*}$, que é uma extensão do teste descrito por Philips (1987). ${ }^{3}$

\subsubsection{Dinâmica de curto prazo, o Modelo Vetorial Autorregressivo (VEC)}

De acordo com o procedimento proposto por Engle e Granger (1987) para estimar o vetor de cointegração, é necessário estimar o VEC, o qual possui a seguinte forma:

$$
\Delta\left(C_{k}\right)_{t}=\alpha_{0}+\sum_{j=1}^{n 1} \alpha_{1 j} \Delta\left(c_{k}\right)_{t-j}+\sum_{j=0}^{n 2} \alpha_{2 j} \Delta z_{2, t-j}+\ldots+\sum_{j=0}^{n 5} \alpha_{5 j} \Delta z_{5, t-j}+\alpha_{6} E C_{t-1}
$$

Sendo que $z_{t}$ é a enésima variável no vetor de cointegração, $E C_{t-1}$ é o termo de correção de erro defasado em um período; o índice $k$ representa os setores residencial, comercial e industrial, logo, $k=r, c$ e $i$.

No contexto da equação (5), a dinâmica de curto prazo é estimada por OLS, ressaltando que a dinâmica de longo prazo é capturada pela introdução dos termos de correção de erros oriundos da estimação dos vetores de cointegração por DOLS e Mudança de Regime.

\subsection{Cenários de previsão}

Ao trabalhar com modelos de previsão, é necessário que existam possíveis cenários para as variáveis independentes que compõem o modelo.

3 Os testes $\mathrm{ADF}^{*}$ e $Z_{\alpha}{ }^{*}$ sugerem período para a quebra estrutural igual ao sugerido por $Z_{t}^{*}$, como esperado por Gregory e Hansen (1996). 
No primeiro trimestre de 2002, a Eletrobrás coordenou um estudo para debater os condicionantes do futuro do mercado de energia elétrica no Brasil e procurou mapear as incertezas sobre a evolução futura da economia brasileira. Para um horizonte de médio e longo prazo, foram abordados pontos como crescimento econômico, racionalização, substituição de energia elétrica por outra fonte de energia e o comportamento das tarifas de energia elétrica.

A partir desta análise, foram construídos três cenários macroeconômicos (alto, médio e baixo) para a economia brasileira, que serviram de base para a previsão do mercado de energia elétrica no Plano Decenal de Expansão 2003-2012 da Eletrobrás.

O Quadro 4 apresenta, de forma resumida, a caracterização desses cenários. ${ }^{4}$

\section{Quadro 4 - Caracterização dos cenários macroeconômicos}

\begin{tabular}{|llll|}
\hline Variáveis & Cenário Alto $(\mathrm{A})$ & Cenário Médio $(\mathrm{B})$ & Cenário Baixo $(\mathrm{C})$ \\
\hline Dinâmica da economia mundial & Recuperação e forte dinamismo & Crescimento moderado & Recuperação \\
Inserção externa do País & Ampla integração competitiva & Ampla e intensa integração & Integração moderada \\
$\begin{array}{l}\text { Distribuição de renda } \\
\text { Privatização da geração de energia }\end{array}$ & Relativa melhoria & Leve melhoria & Melhoria significativa \\
elétrica & Ampla, mas gradual & Somente nova geração & Mínima \\
Crescimento econômico & Elevado & Médio & Reduzido \\
\hline
\end{tabular}

Fonte: Sumário Executivo do Plano Decenal 2003-2012 da Eletrobrás.

Baseando-se nessas hipóteses, foram estabelecidos os seguintes valores para o crescimento do PIB para a região Nordeste, no horizonte de previsão 2005-2010, como pode ser visto na Tabela 1.

Tabela 1 - Crescimento anual do PIB do Nordeste, em \%

\begin{tabular}{ccc}
\hline Cenário & $2005-2007$ & $2007-2010$ \\
\hline A & 5.0 & 6.7 \\
B & 4.4 & 5.3 \\
C & 1.4 & 2.7 \\
\hline
\end{tabular}

Fonte: Sumário Executivo do Plano Decenal 2003-2012 da Eletrobrás.

Em relação ao crescimento populacional, o Plano Decenal de Expansão 2003-2012 fez uso das taxas de crescimento populacional registradas no Censo Demográfico de 2000 do IBGE. Logo, foi considerado um único cenário demográfico para o Nordeste, como apresentado na Tabela 2.

Tabela 2 - Crescimento anual da população do Nordeste, em \%

\begin{tabular}{ccc}
\hline Cenário & $2005-2007$ & $2007-2010$ \\
\hline Único & 1.17 & 1.12 \\
\hline
\end{tabular}

Fonte: Sumário Executivo do Plano Decenal 2003-2012 da Eletrobrás.

4 Este trabalho assumiu os mesmos cenários descritos acima para o mercado de energia elétrica, uma vez que a elaboração de cenários não é o objetivo deste estudo, e também porque a utilização destes cenários permite comparar as previsões feitas pela Eletrobrás e por SCC (2006). 
No que se refere às demais variáveis do mercado de energia elétrica, adotou-se aqui os mesmos valores estabelecidos por Schmidt e Lima (2004) para o caso das tarifas médias e dos preços de eletrointensivos (recuperação real de $5 \%$ ao ano), bem como a manutenção ao nível de 1999 dos preços reais de bens intensivos em energia elétrica e dos combustíveis.

\section{ANÁLISE EMPÍRICA}

A seguir, são apresentados os resultados obtidos com as técnicas de DOLS e Mudança de Regime, iniciando-se pelo teste de raiz unitária, desenvolvido por Elliot, Rothenbeg e Stock (1996), e conhecido como Dickey-Fuller - GLS, cuja finalidade é testar a estacionariedade e a ordem de integração das variáveis do modelo.

Posteriormente, verifica-se se há cointegração entre as séries escolhidas. Quando duas (ou mais) séries são cointegradas, pode-se dizer que há uma relação de longo prazo entre elas. Dessa maneira, os coeficientes do vetor cointegrante encontrados são as elasticidades de longo prazo da demanda por energia elétrica, as quais serão estimadas por DOLS e Mudança de Regime.

Havendo cointegração entre as séries, pode-se estimar um VEC que verifica, entre outras coisas, a velocidade de ajustamento dos desvios em relação ao equilíbrio de longo prazo.

A partir dos VEC estimados, são feitas previsões para o consumo de energia elétrica para as classes residencial, comercial e industrial da região Nordeste do Brasil para o período de 2004 a 2010.

\subsection{Testes de raiz unitária e cointegração}

Primeiramente, é necessário examinar se existe uma relação de equilíbrio entre as variáveis que compõem a equação (3). Para isso, utilizou-se o teste de raiz unitária conhecido como Dickey-Fuller - GLS, desenvolvido por Elliot, Rothenberg e Stock (1996). Tal teste modifica os trabalhos de Fuller (1977) e Dickey e Fuller (1979), melhorando substancialmente o poder do teste quando há, na série, uma média ou tendência não identificada ou desconhecida. Além disso, experimentos de Monte Carlo mostram que o teste modificado desenvolve-se satisfatoriamente em pequenas amostras, o que justifica sua utilização no caso do presente trabalho, o qual dispõe de apenas 34 observações.

No entanto, algumas séries estatísticas podem exibir mais de uma raiz unitária. Neste caso, deve-se examinar a ausência de estacionariedade partindo de um teste para o número máximo de raízes unitárias e não para o mínimo. Caso contrário, é possível que se conclua erroneamente que a série não possui nenhuma raiz unitária ou que ela contém apenas uma raiz. A metodologia a ser empregada neste caso, portanto, é do geral para o específico, ou seja,

5 Estes valores estão de acordo com os estabelecidos por SCC (2006). 
escolhe-se uma determinada ordem de diferenciação da série e aplica-se o teste recursivamente até chegar à série em nível (DICKEY; PANTULA, 1987; PATTERSON, 2000).

Os resultados dos testes, começando com a segunda diferença das séries, sugerem que a hipótese nula de raiz unitária só é rejeitada a um nível de 5\% de significância para as variáveis em nível. No entanto, rejeita-se a hipótese nula em segunda e primeira diferença para todas elas. Logo, as variáveis são integradas de ordem 1 (Anexo I). Sendo assim, é possível que exista uma relação de longo prazo entre elas.

De acordo com o teste de cointegração proposto por Johansen (1988 e 1991), foi detectada, para as três classes - residencial, comercial, e industrial -, a existência de vetores cointegrantes; logo, a hipótese nula de que não existe cointegração é rejeitada ao nível de 5\% de significância. Sendo assim, os vetores cointegrantes foram obtidos pela metodologia desenvolvida por Stock e Watson (1993), DOLS, e por um modelo que permite mensurar, caso exista, uma possível mudança de regime através do procedimento descrito por Gregory e Hansen (1996).

\subsection{Estimação do vetor de cointegração por DOLS e mudança de regime}

As Tabelas 3 a 5 apresentam os vetores de cointegração para a classe residencial, comercial e industrial, respectivamente. ${ }^{6}$

Tabela 3 - Vetor cointegrante, demanda por energia elétrica residencial

\begin{tabular}{|c|c|c|c|c|}
\hline \multirow{2}{*}{ Variável } & \multicolumn{2}{|c|}{ DOLS* } & \multicolumn{2}{|c|}{ Mudança por Regime** } \\
\hline & Coeficiente & Estatística - $\mathrm{t}$ & Coeficiente & Estatística - t \\
\hline $\mathrm{C} 1$ & 5.6406 & 2.1896 & 1.8409 & 0.7047 \\
\hline C2 & - & - & 2.0538 & 28.7245 \\
\hline $\operatorname{Tr}$ & -0.6872 & 7.9537 & -0.5043 & 4.7352 \\
\hline Yp & 0.6840 & 3.8362 & 0.8767 & 5.5138 \\
\hline PER & -0.8393 & 11.9388 & -0.7049 & -5.4390 \\
\hline
\end{tabular}

Fonte: Resultados obtidos utilizando-se o software Gauss.

Nota: $\left({ }^{*}\right)$ AIC, $\left.\mathrm{k}=2 .{ }^{* *}\right)$ AIC, $\mathrm{k}=1$. Data da quebra 1988, $\mathrm{t}=19$. Teste $\mathrm{Z}_{\mathrm{t}}$.

De acordo com a Tabela 3, no modelo residencial, as elasticidades são todas estatisticamente significativas e os sinais obtidos estão de acordo com o esperado para o vetor estimado por DOLS, ou seja, a tarifa de energia elétrica residencial e o preço dos eletrodomésticos são negativamente correlacionados com a demanda por energia elétrica, enquanto a renda familiar é positivamente correlacionada. Um aumento de $1 \%$, por exemplo, na renda familiar faz com que a demanda por energia elétrica aumente em $0,684 \%$. No vetor com mudança de regime apenas $\mathrm{C} 1$, o consumo autônomo é estatisticamente insignificante.

A Tabela 4 apresenta os coeficientes (elasticidades-renda e preço do consumo de energia elétrica) do vetor de cointegração para a classe comercial. Os sinais estão de acordo com o esperado, exceto PEC para o modelo com Mudança de Regime. Na estimação do vetor de cointe-

6 Ver Anexo II para uma tabela completa, com leads e lag. 
gração por DOLS, a variável que mensura a elasticidade-preço das máquinas e equipamentos elétricos para a classe comercial apresentou um resultado estatisticamente insignificante. ${ }^{7}$ Logo, a demanda comercial é explicada pelo consumo de subsistência, pela tarifa média e pelo produto comercial.

Tabela 4 - Vetor cointegrante, demanda por energia elétrica comercial

\begin{tabular}{|c|c|c|c|c|}
\hline \multirow{2}{*}{ Variável } & \multicolumn{2}{|c|}{ DOLS* } & \multicolumn{2}{|c|}{ Mudança de Regime** } \\
\hline & Coeficiente & Estatística - t & Coeficiente & Estatística - t \\
\hline $\mathrm{C} 1$ & 5.2677 & 1.0766 & -0.3440 & 0.1756 \\
\hline $\mathrm{C} 2$ & - & - & 0.6309 & 8.4798 \\
\hline $\mathrm{Tc}$ & -0.9752 & -2.0419 & -1.2017 & -5.8505 \\
\hline Yc & 1.1028 & 4.7048 & 1.4288 & 15.0242 \\
\hline PEC & - & - & 0.5151 & 2.4646 \\
\hline
\end{tabular}

Fonte: Resultados obtidos utilizando-se o software Gauss.

Nota: *AIC, $\mathrm{k}=1$. ** AIC, $\mathrm{k}=0$. Data da quebra 1984, $\mathrm{t}=15$. Teste $\mathrm{Z}_{\mathrm{t}}$.

$\mathrm{Na}$ Tabela 5, referente ao modelo industrial, as elasticidades são todas estaticamente significantes. Todos os sinais estão de acordo com o esperado, exceto o preço das máquinas e equipamentos elétricos da indústria para o DOLS, cujo sinal esperado é negativo, o que contraria o resultado obtido por SCC (2006). Este resultado pode estar sendo influenciado pela quebra estrutural ocorrida em 1985, sugerida pelo vetor com Mudança de Regime. O fato é que, quando a equação é estimada levando em conta a mudança de regime, o coeficiente do preço de máquinas e equipamentos apresenta o sinal esperado.

Tabela 5 - Vetor cointegrante, demanda por energia elétrica industrial

\begin{tabular}{lccccc}
\hline \multirow{2}{*}{ Variável } & \multicolumn{2}{c}{ DOLS $^{*}$} & & \multicolumn{2}{c}{ Mudança de Regime $^{* *}$} \\
\cline { 2 - 3 } & Coeficiente & Estatística $-\mathrm{t}$ & & Coeficiente & Estatística $-\mathrm{t}$ \\
\hline $\mathrm{C} 1$ & 8.0293 & 3.4778 & & 7.7630 & 5.5308 \\
$\mathrm{C} 2$ & - & - & & 8.0954 & 111.2005 \\
$\mathrm{Ti}$ & -3.7064 & -4.2359 & & -1.0708 & -3.1606 \\
$\mathrm{Yi}$ & 1.2071 & 5.7867 & & 1.2040 & 9.7727 \\
$\mathrm{PEI}$ & 0.9650 & 2.5747 & & -0.5818 & 2.8202 \\
$\mathrm{PC}$ & 0.5079 & 3.5567 & & 0.5656 & 6.3408 \\
\hline
\end{tabular}

Fonte: Resultados obtidos utilizando-se o software Gauss.

Nota: *AIC, $\mathrm{k}=2$. ${ }^{*}$ AIC, $\mathrm{k}=1$. Data da quebra $1985, \mathrm{t}=16$. Teste $\mathrm{Z}_{\mathrm{t}}$.

\subsection{Modelos vetoriais autorregressivos (VEC) para a demanda por energia elétrica}

As Tabelas 6, 7 e 8 reportam os resultados dos VEC para o setor residencial, comercial e industrial, respectivamente. As defasagens (lags) são escolhidas por meio da minimização do critério AIC, sendo que o número máximo de defasagens foi de $k=3$.

7 O mesmo resultado foi encontrado por SCC (2006). 
Os coeficientes de $E C_{t-1}$ nos três modelos (residencial, comercial e industrial) são estatisticamente significantes, sugerindo que, após um determinado choque, o sistema se ajusta para o equilíbrio de longo prazo. Sendo assim, para o modelo residencial, o valor estimado de $(-0.2267)$, por DOLS, significa que aproximadamente $23 \%$ do desequilíbrio de curto prazo em relação à trajetória de longo prazo da demanda residencial são corrigidos anualmente, ou seja, os desequilíbrios de curto prazo serão corrigidos em pouco mais de quatro anos.

Tabela 6 - Resultados da estimação do VEC: residencial

\begin{tabular}{llclcc}
\hline \multirow{2}{*}{ Variável } & \multicolumn{2}{c}{ DOLS $^{*}$} & & \multicolumn{2}{c}{ Mudança de Regime $^{\star \star}$} \\
\cline { 2 - 3 } & Coeficiente & Estatística $-\mathrm{t}$ & & Coeficiente & Estatística $-\mathrm{t}$ \\
\hline Constante & 0.0369 & 3.2601 & & 0.0390 & 3.4302 \\
$\Delta \mathrm{Cr}(-1)$ & 0.0707 & 0.3634 & & 0.2249 & 1.4248 \\
$\Delta \mathrm{Tr}$ & -0.2078 & -2.9837 & & -0.2696 & -3.6083 \\
$\Delta \mathrm{Yp}$ & 0.0127 & 0.1325 & & 0.0426 & 0.4462 \\
$\Delta \mathrm{PEC}$ & -0.2349 & -1.9278 & & -0.1429 & -1.4251 \\
$\mathrm{EC}(-1)$ & -0.2267 & -2.4015 & & -0.2273 & -2.4706 \\
\hline
\end{tabular}

Fonte: Resultados obtidos utilizando-se o software Gauss.

$\left({ }^{*}\right) \mathrm{AIC}=-2.3871, \mathrm{R}^{2}=0.4628 ;(* *) \mathrm{AIC}=-2.3909, \mathrm{R}^{2}=0.4675$.

Nota: $\mathrm{o}$ valor entre parênteses se refere à defasagem da variável. $\Delta$ refere-se à primeira diferença da variável.

Para o modelo comercial com Mudança de Regime, a correção de desequilíbrios de curto prazo é de $33 \%$ ao ano, implicando que, para a correção de desequilíbrios de curto prazo, é preciso aproximadamente três anos para que o consumo de energia volte à sua trajetória de longo prazo, como se observa na Tabela 7; enquanto que, para o VEC - DOLS, é necessário aproximadamente cinco anos para que os desequilíbrios de curto prazo sejam corrigidos.

Tabela 7 - Resultados da estimação do VEC: comercial

\begin{tabular}{|c|c|c|c|c|}
\hline \multirow{2}{*}{ Variável } & \multicolumn{2}{|c|}{ DOLS $^{*}$} & \multicolumn{2}{|c|}{ Mudança de Regime** } \\
\hline & Coeficiente & Estatística - t & Coeficiente & Estatística - t \\
\hline Constante & 0.0169 & 0.8366 & 0.0577 & 4.0881 \\
\hline$\Delta \mathrm{Cc}(-1)$ & -0.1605 & -0.7187 & 0.0176 & 0.1104 \\
\hline$\Delta \mathrm{Cc}(-2)$ & 0.2282 & 1.2203 & - & - \\
\hline$\Delta \mathrm{Cc}(-3)$ & 0.4012 & 1.7969 & - & - \\
\hline$\Delta \mathrm{Tc}$ & -0.5241 & -3.6472 & -0.5385 & -3.2630 \\
\hline$\Delta \mathrm{Tc}(-1)$ & -0.1242 & -0.7833 & -0.3272 & -2.3542 \\
\hline$\Delta \mathrm{Yc}$ & 0.1591 & 1.4715 & 0.2382 & 2.1757 \\
\hline$\triangle \mathrm{PEC}$ & - & - & -0.0745 & -0.6328 \\
\hline $\mathrm{EC}(-1)$ & -0.1952 & -2.0247 & -0.3272 & -2.3542 \\
\hline
\end{tabular}

Fonte: Resultados obtidos utilizando-se o software Gauss.

$\left.\left({ }^{*}\right) \mathrm{AIC}=-2.1965, \mathrm{R}^{2}=0.4071 ;{ }^{* *}\right) \mathrm{AIC}=-2.3407, \mathrm{R}^{2}=0.4469$.

Nota: o valor entre parênteses se refere à defasagem da variável. $\Delta$ refere-se à primeira diferença da variável. 
Por último, o modelo industrial indica que $61.21 \%$ dos desequilíbrios de curto prazo em relação à trajetória de longo prazo são corrigidos anualmente com correção completa em um intervalo de um pouco menos de dois anos, para o modelo com Mudança de Regime. Para o VEC - DOLS, a correção é um pouco inferior a cinco anos.

Tabela 8 - Resultados da estimação do VEC: industrial

\begin{tabular}{|c|c|c|c|c|}
\hline \multirow{2}{*}{ Variáveis } & \multicolumn{2}{|c|}{ DOLS $^{*}$} & \multicolumn{2}{|c|}{ Mudança de Regime** } \\
\hline & Coeficiente & Estatística - t & Coeficiente & Estatística - t \\
\hline Constante & 0.0357 & 2.9340 & 0.0332 & 2.5121 \\
\hline$\Delta \mathrm{Ci}(-1)$ & -0.2874 & -1.6920 & 0.1965 & 1.6909 \\
\hline$\Delta \mathrm{Ti}$ & -0.4222 & -2.1728 & -0.4273 & -2.8222 \\
\hline$\Delta Y i$ & 0.5746 & 4.3218 & 0.6293 & 4.9547 \\
\hline$\Delta \mathrm{Yi}(-1)$ & 0.1293 & 1.0114 & - & - \\
\hline$\Delta \mathrm{Yi}(-2)$ & 0.4168 & 3.7075 & - & - \\
\hline$\Delta \mathrm{Yi}(-3)$ & 0.3579 & 2.5491 & - & - \\
\hline$\Delta \mathrm{PEI}$ & -0.0003 & -0.0021 & -0.2979 & -2.4372 \\
\hline$\Delta \mathrm{PC}$ & 0.1868 & 2.9150 & 0.2286 & 3.1772 \\
\hline$\Delta \mathrm{PC}(-1)$ & 0.1695 & 2.1008 & - & - \\
\hline EC(-1) & -0.2124 & -2.69 & -0.6121 & -4.9364 \\
\hline
\end{tabular}

Fonte: Resultados obtidos utilizando-se o software Gauss.

$(*) \mathrm{AIC}=-1.9117, \mathrm{R}^{2}=0.5802 ;(*) \mathrm{AIC}=-2.1491, \mathrm{R}^{2}=0.6451$.

Nota: o valor entre parênteses se refere à defasagem da variável. $\Delta$ refere-se à primeira diferença da variável.

Estas correções de desequilíbrios de longo prazo sugerem que o setor residencial se ajusta mais rapidamente que o setor comercial e industrial a desequilíbrios causados no consumo de energia elétrica pelas tarifas, renda, preço de máquinas e equipamentos elétricos e de combustíveis, isto para o VEC - DOLS; entretanto, para o VEC - Mudança de Regime, o ajustamento é mais rápido para o setor industrial $61.21 \%$ ao ano.

Cabe ressaltar que os coeficientes das variáveis diferenciadas nas equações do VEC fornecem diretamente as elasticidades-renda e preço de curto prazo (ETTESTOL, 2002).

\subsection{Análise comparativa das elasticidades estimadas}

Esta subseção realiza uma análise comparativa das elasticidades-renda e preço, obtidos neste estudo para a demanda por energia elétrica da região Nordeste do Brasil, com as que foram apresentadas por SCC (2006). Além desta comparação, são apresentados alguns resultados de outros estudos, ${ }^{8}$ mesmo que estas elasticidades não sejam diretamente comparáveis, devido às especificidades de cada modelo em termos de diferenças em relação às variáveis utilizadas, ao período amostral, à base de dados e às hipóteses consideradas.

8 Modiano (1984), Andrade e Lobão (1997), Braga (2001) e Schmidt e Lima (2004). 
De acordo com os resultados apresentados na Tabela 9 para o consumo da classe residencial, é possível observar que, exceto em Andrade e Lobão (1997), as elasticidades-preço e renda de curto prazo são inferiores às elasticidades de longo prazo, em valor absoluto.

Tabela 9 - Elasticidade-preço e renda para a classe residencial

\begin{tabular}{|c|c|c|c|c|}
\hline \multirow[t]{2}{*}{ Estudos } & \multicolumn{2}{|c|}{ Elasticidade-preço } & \multicolumn{2}{|c|}{ Elasticidade-renda } \\
\hline & $\mathrm{CP}$ & LP & $\mathrm{CP}$ & LP \\
\hline DOLS - NE & -0.2078 & -0.6872 & 0.0127 & 0.6840 \\
\hline Mudança de regime - NE & -0.2696 & -0.5043 & 0.0426 & 0.8767 \\
\hline 1 - Siqueira, Cordeiro Jr. e Castelar (2006), NE & -0.298 & -0.412 & 0.181 & 1.400 \\
\hline \multicolumn{5}{|l|}{2 - Brasil } \\
\hline 2.1 - Modiano (1984) & -0.118 & -0.403 & 0.332 & 1.130 \\
\hline 2.2 - Andrade e Lobão (1997) & -0.060 & -0.051 & 0.212 & 0.210 \\
\hline 2.3 - Schmidt e Lima (2004) & & -0.085 & & 0.530 \\
\hline \multicolumn{5}{|l|}{2.4 - Braga (2001) } \\
\hline a) Norte & & & & 0.370 \\
\hline b) Nordeste & & & & 0.350 \\
\hline c) Sul & & & & 0.600 \\
\hline d) Sudeste & & & & 0.500 \\
\hline
\end{tabular}

Fonte: Elaborada pelos autores.

As elasticidades-preço de curto prazo são inferiores às apresentadas por SCC (2006) e superior aos resultados de Modiano (1984) e Schmidt e Lima (2004). Por sua vez, a elasticidadepreço de longo prazo para o Nordeste, gerado pelo VEC - DOLS e Mudança de regime são superiores às dos demais estudos.

Em relação às elasticidades-renda de curto prazo, as geradas neste estudo são inferiores em relação às demais, sendo todas inelásticas. As de longo prazo são inelásticas (menor do que um, em valor absoluto), enquanto as apresentadas por SCC (2006) e Modiano (1984) são elásticas (maior do que um, em valor absoluto). Em Andrade e Lobão (1997), Schmidt e Lima (2004) e Braga (2001), as elasticidades-renda de longo prazo são inelásticas e inferiores aos resultados desse trabalho.

Ainda na referida tabela, a elasticidade-preço de longo prazo (-0.6872) apresenta um valor inferior em módulo à elasticidade-preço dos eletrodomésticos (-0.8393), sugerindo, desta forma, que um impacto nos preços dos eletrodomésticos tem um efeito maior no consumo do que um impacto no preço de energia elétrica. Esta análise corrobora os resultados apresentados por Schmidt e Lima (2004), bem como os de SCC (2006).

A Tabela 10, em consonância com a anterior, apresenta os resultados das elasticidades-preço e renda de curto e longo prazo da demanda comercial. Em primeiro lugar, vale ressaltar que,

9 Esta análise contempla as elasticidades geradas por DOLS. 
como no caso da demanda residencial, a demanda comercial apresenta as elasticidades-preço e renda de curto prazo inferiores às de longo prazo.

No que se refere às elasticidades-preço de curto e longo prazos, tanto as obtidas por DOLS quanto as obtidas por Mudança de Regime, estas se mostraram mais elásticas para a classe comercial. Um resultado significativo, posto que um pouco distinto dos demais estudos, sendo a elasticidade-preço de longo prazo de -1.2017 em relação ao consumo de energia. Isto implica que um aumento de $1 \%$ da tarifa reduz a demanda por energia em $1.2017 \%$.

As elasticidades-renda de curto prazo, obtidas por Mudança de Regime, apresentam valores entre os trabalhos de SCC (2006) e Modiano (1984); por sua vez, o resultado da estimação por DOLS é inferior aos trabalhos citados. No longo prazo, o resultado obtido por Mudança de Regime é o mais elástico (1.4288), seguido pela estimativa DOLS (1.1028), em relação aos estudos de SCC (2006) e Modiano (1984), que apresentaram resultados próximos, (1.019) e (1.068), respectivamente. ${ }^{10}$

Tabela 10 - Elasticidade-preço e renda para a classe comercial

\begin{tabular}{|c|c|c|c|c|}
\hline \multirow{2}{*}{ Estudos } & \multicolumn{2}{|c|}{ Elasticidade-preço } & \multicolumn{2}{|c|}{ Elasticidade-renda } \\
\hline & $\mathrm{CP}$ & LP & $\mathrm{CP}$ & LP \\
\hline DOLS - NE & -0.5241 & -0.9752 & 0.1591 & 1.1028 \\
\hline Mudança de regime - NE & -0.5385 & -1.2017 & 0.2382 & 1.4288 \\
\hline 1 - Siqueira, Cordeiro Jr. e Castelar (2006), NE & -0.237 & -0.502 & 0.165 & 1.019 \\
\hline \multicolumn{5}{|l|}{2 - Brasil } \\
\hline 2.1 - Modiano (1984) & -0.062 & -0.183 & 0.362 & 1.068 \\
\hline 2.2 - Schmidt e Lima (2004) & & -0.174 & & 0.636 \\
\hline
\end{tabular}

Fonte: Elaborada pelos autores.

No que concerne aos resultados para o consumo da classe industrial apresentados na Tabela 11, pode-se observar que há uma concordância com os demais resultados em relação à magnitude das elasticidades de curto e de longo prazo; sendo as de curto prazo inferiores (em valor absoluto) às elasticidades de longo prazo, com exceção ao trabalho de Modiano (1984).

A elasticidade-preço de longo prazo, obtida por DOLS, é bastante elástica em relação ao consumo, enquanto que os demais estudos apresentaram elasticidade-preço inelástica em relação ao mesmo. Este resultado indica que, por exemplo, para uma variação de $1 \%$ na tarifa, o consumo industrial diminui 3.7064\%, ou seja, o consumo industrial é extremamente sensível a variações nas tarifas no longo prazo. Isto sugere que a indústria substitui a energia elétrica por outra fonte alternativa caso a tarifa suba no longo prazo.

10 A elasticidade-renda de longo prazo apresentada por Schmidt e Lima (2004) é inelástica em relação ao consumo comercial, (0.636). 
Tabela 11 - Elasticidade-preço e renda para a classe industrial

\begin{tabular}{llllll}
\hline \multirow{2}{*}{ Estudos } & \multicolumn{2}{c}{ Elasticidade-preço } & & \multicolumn{2}{c}{ Elasticidade-renda } \\
\cline { 5 - 6 } & CP & LP & & CP & LP \\
\hline DOLS - NE & -0.4222 & -3.7064 & & 0.5746 & 1.2071 \\
Mudança de Regime - NE & -0.4272 & -1.0708 & & 0.6293 & 1.2040 \\
1- Siqueira, Cordeiro Jr. e Castelar (2006), NE & -0.342 & -0.445 & & 0.352 & 1.181 \\
2- Brasil & & & & \\
2.1 - Modiano (1984) & -0.451 & -0.222 & & 0.502 & 1.360 \\
2.2 - Schmidt e Lima (2004) & & -0.545 & & 1.916 \\
\hline
\end{tabular}

Fonte: Elaborada pelos autores.

A elasticidade-preço obtida pela Mudança de Regime também é elástica (-1.0708), porém menos sensível do que a obtida por DOLS. Este resultado ainda está um pouco distantes dos apresentados pelos demais estudos.

Por outro lado, as elasticidades-preço de curto prazo, (-0.4222) e (-0.4272), oriundas das estimações por DOLS e Mudança de Regime, respectivamente, são mais inelásticas do que as apresentadas por Modiano (1984), e mais elásticas do que os resultados de SCC (2006). Como elas apresentam um valor baixo, isto implica que a resposta do consumo industrial em relação às alterações no preço de energia elétrica no curto prazo é pequena, o que pode ser justificado pela inexistência de um bem substituto a curto prazo para energia elétrica na classe industrial.

A elasticidade-preço de máquinas e equipamentos elétricos para a indústria $(-0.5818)$ apresenta um valor inferior à elasticidade-preço da energia elétrica (-1.0708), sugerindo que um impacto positivo nos preços das máquinas e equipamentos elétricos causa um efeito menor no consumo do que um aumento na tarifa; sendo assim, a tarifa é mais elástica do que o preço de máquinas e equipamentos elétricos para a indústria, isto para as estimações por Mudança de Regime.

Na classe industrial, foi também levado em consideração o preço dos combustíveis, considerados como substitutos da energia elétrica. As elasticidades-preço dos combustíveis obtidas nesse estudo, por DOLS e Mudança de Regime, foram de (0.5656) e (0.5079), respectivamente, ou seja, são inelásticas em relação ao consumo de energia elétrica. Uma inferência desse resultado é que, para a indústria nordestina, o consumo de energia elétrica sofre pouca influência das variações no preço desses bens; logo, a indústria nordestina não faz uso de fontes alternativas de energia. Este resultado corrobora aquele apresentado por SCC (2006) para o Nordeste (0.174), e é contrário ao estudo de Schmidt e Lima (2004), que encontraram uma elasticidade negativa para o Brasil.

Em relação às elasticidades-renda, verifica-se que, no curto prazo, a obtida por DOLS (0.5746) é menos sensível que no modelo com Mudança de Regime (0.6293), seguido dos resultados apresentados por Modiano (1984) e SCC (2006), (0.502) e (0.352), respectivamente. 
Mesmo assim, se apresenta de forma inelástica em relação ao consumo; dado que a modificação observada no consumo é pequena em relação a uma variação na renda.

Ao comparar a elasticidade-renda de longo prazo, verifica-se que o resultado apresentado por SCC (2006) é menor do que o obtido por DOLS e por Mudança de Regime, (1.181), (1.2071) e (1.2040), respectivamente. Sendo assim, as metodologias aplicadas neste trabalho apresentam uma maior sensibilidade das elasticidades-renda de longo prazo em relação ao consumo.

Quando comparada com as elasticidades-renda apresentadas por Modiano (1984) e Schmidt e Lima (2004), percebe-se que tanto as obtidas por DOLS quanto por Mudança de Regime são inferiores às mesmas (1.360) e (1.916), respectivamente. No entanto, as elasticidades apresentadas por Modiano (1984) e Schmidt e Lima (2004) referem-se ao mercado de energia elétrica brasileiro, enquanto esta pesquisa se propôs a analisar especificamente o mercado da região Nordeste do Brasil.

De uma maneira geral, verifica-se que a classe residencial apresentou elasticidades-preço menores do que a classe comercial e industrial, tanto no curto quanto no longo prazo, para os dois métodos de estimação. Em relação às elasticidades-renda, o consumo industrial apresentou uma maior resposta à renda (1.2071) no longo prazo, quando comparado com o consumo nas classes residencial $(0.6840)$ e comercial (1.1028), isto no caso dos resultados gerados por DOLS.

Quanto aos resultados gerados pelo modelo que incorpora uma quebra estrutural, a classe comercial é a que exibe resultados mais elásticos em relação às elasticidades-renda de longo prazo, dentre as classes analisadas. Portanto, a classe comercial apresentou a maior resposta no consumo, dada uma variação na renda (1.4288).

A partir da análise comparativa dos resultados obtidos, tanto com DOLS quanto com OLS com quebra estrutural, e os resultados apresentados por SCC (2006), é primordial ressaltar que os dois primeiros não fizeram uso da hipótese de recuperação do consumo de energia elétrica para nenhuma das classes, enquanto que SCC (2006) utilizaram uma variável dummy de intercepto não-binária, contida no intervalo entre zero e um; ou seja, $0 \leq D_{i} \leq 1$, para modelar a taxa de recuperação correspondente ao biênio 2002/2003. ${ }^{11}$

Em suma, quando comparadas as elasticidades-preço obtidas neste trabalho por DOLS com as apresentadas por SCC (2006), verifica-se que somente a elasticidade-preço de curto prazo para a classe residencial tem valor menor em módulo. Isto implica que as variações na tarifa causam pouco impacto no consumo de energia. Por outro lado, as elasticidades-renda de curto e longo prazo para a classe residencial são inferiores aos resultados apresentados por SCC (2006).

11 Para a determinação dessa taxa, calcula-se a diferença entre o valor previsto, a partir das elasticidades obtidas com os dados pré-racionamento (1970-2000) - VP1 - e os valores reais, observados nos anos de 2002 e 2003, supondo que, nos próximos anos, a variação na diferença entre os valores VP1 e o valor real ocorra a uma taxa constante que segue um decrescimento geométrico, para tentar modelar a mudança introduzida na série pelo referido racionamento. 
A classe residencial com Mudança de Regime apresenta elasticidades-preço e renda inferiores no curto e no longo prazo, ao se comparar com os resultados de SCC (2006), com exceção para a elasticidade-preço de longo prazo. Em relação à classe comercial, a análise se inverte, ou seja, este estudo obteve resultados mais elásticos do que os apresentados por SCC (2006). E, por fim, a classe industrial apresenta resultados mais elásticos para as elasticidades-preço e renda do que as apresentadas por SCC (2006), no curto e no longo prazo.

\section{Previsóes}

Nesta seção, apresenta-se um exercício de previsão para a demanda por energia elétrica feita para as classes residencial, comercial e industrial para a região Nordeste do Brasil, de 2004 a 2010, utilizando VEC.

Embora o consumo real para o período 2004 a 2006 já esteja disponível, ele foi projetado para que se pudesse averiguar a capacidade de previsão dos modelos DOLS e Mudança de Regime através de uma comparação entre o valor previsto e o observado. Isso é conhecido como previsão ex post. Já com relação ao período 2007/2010, como não se tem o conhecimento da demanda, esta é chamada de previsão ex ante.

Cada classe de consumo apresenta certas peculiaridades; sendo assim, a previsão de demanda será direcionada a cada tipo de classe, buscando representar o comportamento da tendência ao longo do período previsto. A classe residencial, por exemplo, não apresenta uma fonte de energia para substituir a energia elétrica. No entanto, a classe industrial tem a sua disposição alguns combustíveis que podem ser considerados como fontes alternativas de energia elétrica.

Ademais, a demanda desta utilidade pública pode evoluir de diferentes formas, dependendo da política tarifária, do nível de renda da classe residencial, do PIB da classe comercial e industrial, dos preços dos eletrodomésticos, das máquinas e equipamentos elétricos e dos combustíveis. Dessa maneira, as previsões foram construídas a partir de três cenários macroeconômicos alternativos, elaborados pela Eletrobrás, utilizando o VEC oriundo dos vetores cointegrantes estimados por DOLS e por Mudança de Regime.

A Tabela 12 traz uma comparação entre os valores observados e as previsões feitas por este estudo, bem como as apresentadas pela Eletrobrás e por SCC (2006) para os anos de 2004/2006. ${ }^{12}$ Dela extrai-se que as previsões elaboradas neste estudo apresentam resultados mais satisfatórios para o ano de 2004, uma vez que as diferenças porcentuais \{[(valor previsto/ valor observado) - 1] *100\} são menores (em valor absoluto) do que as que foram calculadas a partir das previsões geradas por SCC (2006) e pela Eletrobrás, utilizando como referência o cenário A.

12 Estas comparações foram feitas utilizando o cenário A descrito pelo Plano Decenal de Expansão 2003 - 2012 elaborado pela Eletrobrás. O Anexo III reporta as previsões para os três cenários por classe de consumo. 
O modelo com Mudança de Regime apresentou a menor diferença porcentual para a classe residencial no período de 2004 a 2006, o que implica previsão mais acurada em relação aos demais modelos, seguido pela previsão do DOLS.

Para a classe comercial, a menor diferença porcentual é a observada também pelo modelo com Mudança de Regime para o período 2004 a 2006. Mais uma vez, a previsão DOLS também se mostrou mais próxima do que as apresentadas pela Eletrobrás e por SCC (2006).

Ainda de acordo com a tabela em epígrafe, para a classe industrial, no ano de 2004, a melhor previsão foi a do modelo com Mudança de Regime seguido por DOLS, SCC (2006) e Eletrobrás. Já, para o ano de 2005, SCC (2006) apresentou a melhor previsão. Enquanto que, para 2006, a melhor previsão foi a da Eletrobrás.

\section{CONSIDERAÇÕES FINAIS}

Este estudo teve como objetivo estimar a demanda por energia elétrica para as classes residencial, comercial e industrial para a região Nordeste do Brasil, durante o período de 1970 a 2003, por meio da metodologia desenvolvida por Stock e Watson (1993), conhecida como DOLS. Tal metodologia estima coeficientes mais robustos por incorporar lags e leads ao vetor de cointegração quando aplicada em pequenas amostras.

Além do DOLS, utilizou-se também uma técnica que permite estimar relações de longo prazo com mudança de regime, desenvolvida por Gregory e Hansen (1996), a qual é uma extensão do procedimento de Engle e Granger (1987). Tal técnica permite determinar de maneira endógena a data na qual ocorreu uma mudança de regime (intercepto), e de que maneira, a partir dessa mudança, o modelo retomaria sua relação de longo prazo.

Para a classe residencial, todos os coeficientes estimados foram estatisticamente significantes, e os sinais calculados estão de acordo com o esperado.

A classe comercial também apresentou sinais de acordo com o esperado e, para a elasticidadepreço de máquinas e equipamentos elétricos, o coeficiente é estatisticamente insignificante; logo, não compõe o vetor de cointegração .

No modelo que explica o setor industrial, as elasticidades-preço e renda foram todas significantes. Apenas o sinal do coeficiente do preço de máquinas e equipamentos apresenta sinal contrário ao esperado. Por sua vez, as estimações dos vetores cointegrantes pela metodologia proposta por Gregory e Hansen (1996) para a classe residencial estão de acordo com o esperado e as elasticidades obtidas são estatisticamente significantes.

A partir das estimações dos VEC, utilizando os vetores cointegrantes gerados por DOLS e por Mudança de Regime, nota-se que o setor industrial apresentou a maior correção anual, na estimação feita por Mudança de Regime, na qual 61.21\% dos desequilíbrios de curto prazo são corrigidos anualmente. Por sua vez, o modelo residencial é o que apresenta a maior correção causada 
por variações na tarifa, na renda e/ou no preço de eletrodomésticos, 22,67\% ao ano, quando se usa VEC - DOLS.

Da comparação com outros trabalhos realizados para o Brasil, conclui-se que os resultados aqui obtidos estão de acordo com a literatura nacional e se mostraram relativamente próximos daqueles gerados pelo trabalho de SCC (2006). Vale ressaltar que esses autores modelaram o consumo pós-racionamento através de uma variável dummy não-binária que segue um decrescimento geométrico, enquanto este estudo estima a demanda por energia elétrica para a região Nordeste através do DOLS, e também através da metodologia proposta por Gregory e Hansen (1996).

Quanto às previsões usando os modelos VEC, gerados por DOLS e por Mudança de Regime, verificou-se que os resultados apresentam menor diferença porcentual em relação aos apresentados por SCC (2006), para os anos de 2004 a 2006, com exceção do ano de 2005 para a classe industrial. Para a classe comercial, o modelo com Mudança de Regime se mostra mais eficaz, em termos de previsão, para o período 2004/06. A previsão da Eletrobrás se mostrou mais próxima do valor observado para o ano de 2005, quando comparado com as do DOLS. No entanto, em 2006, a previsão do DOLS supera a da Eletrobrás em termos de eficiência (menor diferença porcentual). Na classe industrial, por sua vez, a previsão feita a partir dos VEC gerados por Mudança de Regime se mostrou mais próxima do valor observado para o ano de 2004. Em 2005, o resultado de SCC (2006) foi o mais acurado; já, em 2006, o resultado da Eletrobrás foi o que apresentou a menor diferença porcentual, seguido pelo DOLS, SCC (2006) e Mudança de Regime.

De uma maneira geral, é legítimo concluir que as previsões geradas neste estudo são mais acuradas do que aquelas apresentadas pela Eletrobrás e por SCC (2006). 


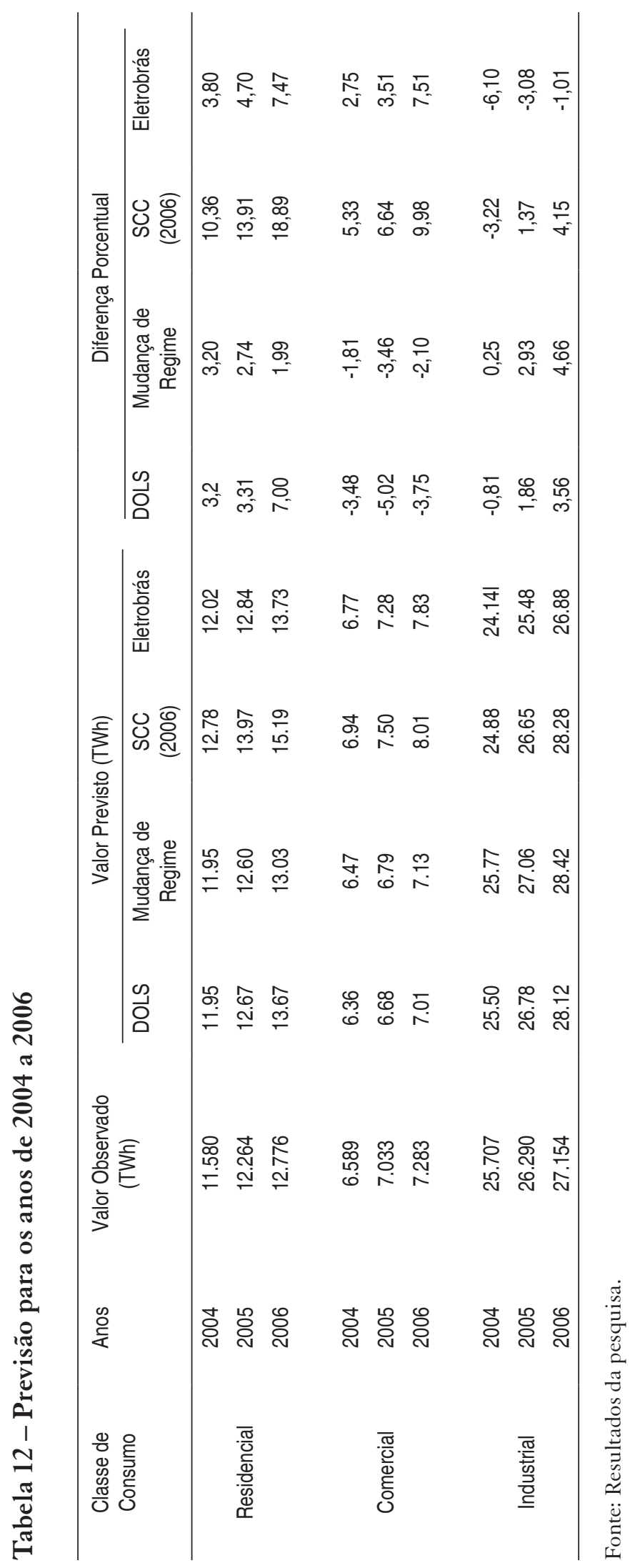




\section{REFERÊNCIAS}

AKMAL, M.; STERN, D. I. Residential energy demand in Australia: an application of dynamic OLS. Australia: Australian National University, Centre for Resource and Environmental Studies, Ecological Economics Program, 2001. (Working Papers in Ecological Economics, n. 0104).

AL-AZZAM, A.; HAWDON, D. Estimating the demand for energy in Jordan: a Stock-Watson dynamic OLS (DOLS) approach. United Kingdom: The University of Surrey, Guildford, Surrey, Surrey Energy Economics Centre, Department of Economics, 1999. (Department of Economics Discussion Papers, n. 97).

ANDRADE, T.; LOBÃO, W. Elasticidade-renda e preço da demanda residencial de energia elétrica no Brasil. Rio de Janeiro: IPEA, 1997. (Texto para Discussão, n. 489).

BRAGA, J. M. A modelagem da demanda residencial de energia elétrica no Brasil. Tese (Mestrado) - UFRJ, Rio de Janeiro, 2001.96 p.

CHOI, W. G.; OH, S. A money demand function with output uncertainty, monetary uncertainty, and financial innovations. Journal of Money, Credit, and Banking, v. 35, n. 5, p. 685-710, 2003.

DICKEY, D. A.; FULLER, W. A. Distribution of the estimators for autoregressive times series with a unit root. Journal of the American Statistical Association, v. 74, p. 427-431, 1979.

DICKEY, D. A.; PANTULA, S. G. Determining the order of differencing in autoregressive processes. Journal of Business and Economic Statistics, v. 5, p. 455-461, 1987.

ELETROBRÁS. Plano decenal de expansão 2003/2012. Rio de Janeiro. 2003. Disponível em: <www. eletrobras.gov.br>.

ELLIOTT, G.; ROTHENBERG, T. J.; STOCK, J. H. Efficient tests for an autoregressive unit root. Econometrica, v. 64, n. 4, p. 813-836, 1996.

ENDERS, W. Applied econometrics time series. New York: John Wiley and Sons, 1995.

ENGLE, R. F.; GRANGER, C. W. J. Co-integration and error correction: representation, estimation and testing. Econometrica, v. 55, p. 251-276, 1987.

ETTESTOL, I. Estimating residential demand for electricity with smooth transition regression. Trondheim, Norway: NTNU, May 2002.

FULLER, W. A. Some properties of a modification of the limited information estimator. Econometrica, v. 45, n. 4, p. 939-953, 1977.

GREENE, W. H. Econometric analysis. Fifth Edition, 2003.

GREGORY, A. W., HANSEN, B. E. Residual-based testes for cointegration in models with regime shift. Journal of Econometrics, v. 70, n. 4, p. 99-126, 1996.

HAMILTON, J. Time series analysis. Princeton: Princeton University Press, 1994.

JOHANSEN, S. Statistical analysis of co-integration vectors. Journal of Economic Dynamic and Control, v. 12, p. 231-254, 1988.

Estimating and hypothesis testing of co-integration vectors in Gaussian vector autoregressive models. Econometrica, v. 59, n. 6, p. 1.551-1.580, 1991.

JOHANSEN, S.; JUSELIUS, K. Maximum likelihood estimation and inference on co-integration - with applications to the demand for money. Oxford Bulletin of Economics and Statistics, v. 52, n. 2, p. 169210, 1990. 
MASIH, R.; MASIH, A. M. M. Stock-Watson dynamic OLS (DOLS) and error-correction modeling approaches to estimating long and short-run elasticities in a demand function: New evidence and methodological implications from an application to the demand for coal in Mainland China. Energy Economics, v. 18, n. 4, p. 315-334, 1996.

MODIANO, E. M. Elasticidade renda e preços da demanda de energia elétrica no Brasil. Rio de Janeiro: Departamento de Economia da PUC, 1984. (Texto para Discussão, n. 68).

PATTERSON, K. An introduction to applied econometrics: a times series approach. St. Martin's Press, 2000.

PINDYCK, R. S. The structure of world energy demand. The Economic Journal, v. 90, Sept. 1980, p. 664665, 1979.

PHILlIPS, P. C. B. Time series regression with a unit root. Econometrica, v. 55, n.2, p. 277-301, 1987.

SAED, A. A. J. Estimation of total energy consumption in Jordan 1980-1999: Evidence from co-integration and stock. Journal of Economic \& Administrative Sciences, v. 20, n. 1, p. 71-82, 2004.

SCHMIDT, C. A. J.; LIMA, M. A. M. A demanda por energia elétrica no Brasil. RBE, Rio de Janeiro, v. 58, n. 1, p. 67-98, 2004.

SCHWERT, G. W. Tests for unit roots: a Monte Carlo investigation. Journal of Business \& Economic Statistics, v. 7, n. 2, p. 147-159, 1989.

SILK, J. I.; JOUTZ, F. L. Short and long-run elasticity's in US residential electricity demand: a cointegration approach. Energy Economics, v. 19, n. 4, p. 493-513, 1997.

SIMS, C. A. Money, income and causality. American Economic Review, v. 62, n. 4, p. 540-552, 1972.

SIQUEIRA, M. L., CORDEIRO JR., H. H.; CASTELAR, I. A demanda por energia elétrica no Nordeste brasileiro após o racionamento de 2001-2002: previsões de longo prazo. Pesquisa e Planejamento Econômico, v. 36, n. 1, p. 137-178, 2006.

STOCK, J. H.; WATSON, M. W. A simple estimator of co-integrating vectors in higher order integrated systems. Econometrica, v. 61, n. 4, p. 783-820, 1993.

ZACHARIADIS, T.; PASHOURTIDOU, N. An empirical analysis of electricity consumption

in Cyprus. Energy Economics, v. 29, n. 2, p. 183-198, 2007. 


\section{ANEXo I}

Tabela 13 - Teste de Raiz Unitária Dickey-Fuller - GLS, classe residencial

\begin{tabular}{lccc}
\hline \multirow{2}{*}{ Variáveis } & $2^{\text {a }}$ Diferença & $1^{\text {a }}$ Diferença & Nível \\
\cline { 2 - 4 } & $t_{(\mu)}$ & $t_{(\mu)}$ & $t_{(\mu)}$ \\
\hline Cr & -6.9738 & -4.1829 & -1.3961 \\
Tr & -7.7948 & -6.4696 & -0.6271 \\
Yp & -6.2383 & -5.2862 & -2.0362 \\
PER & -6.4678 & -5.6715 & -2.1244 \\
\hline & & Valores Críticos $(5 \%)$ & \\
\hline Cr & -3.19 & -3.19 & -3.19 \\
Tr & -3.19 & -3.19 & -3.19 \\
Yp & -3.19 & -3.19 & -3.19 \\
PER & -3.19 & -3.19 & -3.19 \\
\hline
\end{tabular}

Fonte: Resultados da pesquisa.

Observações: A estatística $t(\mu)$ refere-se aos modelos com intercepto e tendência.

Utilizou-se o critério de informação de Schwartz para a escolha de defasagem para cada variável testada.

Os valores críticos foram obtidos em Elliott-Rothenberg-Stock (1996, Table 1).

Tabela 14 - Teste de Raiz Unitária Dickey-Fuller - GLS, classe comercial

\begin{tabular}{lccc}
\hline \multirow{2}{*}{ Variáveis } & 2a Diferença & 1- Diferença & Nível \\
\cline { 2 - 4 } & $t(\mu)$ & $t(\mu)$ & $t(\mu)$ \\
\hline Cc & -6.8922 & -4.9124 & -1.4573 \\
Tc & -5.7938 & -5.0968 & -1.0508 \\
Yc & -5.6717 & -4.9835 & -2.2698 \\
PEC & -8.6387 & -5.8792 & -2.2843 \\
\hline & & Valores Críticos $(5 \%)$ & -3.19 \\
\hline Cc & -3.19 & -3.19 & -3.19 \\
Tc & -3.19 & -3.19 & -3.19 \\
Yc & -3.19 & -3.19 & -3.19 \\
PEC & -3.19 & -3.19 & \\
\hline
\end{tabular}

Fonte: Resultados da pesquisa.

Observações: A estatística $t(\mu)$ refere-se aos modelos com intercepto e tendência.

Utilizou-se o critério de informação de Schwartz para a escolha de defasagem para cada variável testada.

Os valores críticos foram obtidos em Elliott-Rothenberg-Stock (1996, Table 1). 
Tabela 15 - Teste de Raiz Unitária Dickey-Fuller - GLS, classe industrial

\begin{tabular}{|c|c|c|c|}
\hline \multirow{2}{*}{ Variáveis } & 2ª Diferença & 1ª Diferença & Nível \\
\hline & $t(\mu)$ & $t(\mu)$ & $t(\mu)$ \\
\hline $\mathrm{Ci}$ & -11.1337 & -6.2780 & -1.3037 \\
\hline $\mathrm{Ti}$ & -6.7101 & -5.9141 & -2.0782 \\
\hline Yi & -7.3497 & -5.6658 & -1.0859 \\
\hline PEI & -6.5126 & -5.2522 & -2.2335 \\
\hline $\mathrm{PC}$ & -7.1279 & -4.1465 & -1.7277 \\
\hline \multicolumn{4}{|c|}{ Valores Críticos (5\%) } \\
\hline $\mathrm{Ci}$ & -3.19 & -3.19 & -3.19 \\
\hline $\mathrm{Ti}$ & -3.19 & -3.19 & -3.19 \\
\hline Yi & -3.19 & -3.19 & -3.19 \\
\hline PEI & -3.19 & -3.19 & -3.19 \\
\hline PC & -3.19 & -3.19 & -3.19 \\
\hline
\end{tabular}

Fonte: Resultados da pesquisa.

Observações: A estatística $t(\mu)$ refere-se aos modelos com intercepto e tendência.

Utilizou-se o critério de informação de Schwartz para a escolha de defasagem para cada variável testada. Os valores críticos foram obtidos em Elliott-Rothenberg-Stock (1996, Table 1) 


\section{ANEXO II}

Tabela 16 - Vetor cointegrante estimado por DOLS, demanda por energia elétrica residencial

\begin{tabular}{lcc}
\hline Variável & Coeficientes & Estatística - $t$ \\
\hline & Vetor Cointegrante & \\
C1 & 5.6406 & 2.1896 \\
Tr & -0.6872 & -7.9537 \\
Yp & 0.684 & 3.8362 \\
PER & -0.8393 & -11.9388 \\
& Leads & \\
Tr (+1) & 0.0854 & 0.8831 \\
Yp (+1) & -0.0376 & -0.2665 \\
PER (+1) & 0.1506 & 1.4101 \\
$\operatorname{Tr}(+2)$ & 0.193 & 1.7372 \\
Yp (+2) & 0.0227 & 0.1420 \\
PER (+2) & -0.3374 & -3.5109 \\
& Lag & \\
$\operatorname{Tr}(-1)$ & 0.3381 & 3.5515 \\
Yp (-1) & -0.6785 & -5.3721 \\
PER (-1) & 0.3183 & 2.4077 \\
$\operatorname{Tr}(-2)$ & 0.2424 & 2.7023 \\
Yp (-2) & -0.5994 & -4.3403 \\
PER (-2) & -0.068 & -0.5094 \\
\hline
\end{tabular}

Fonte: Resultados obtidos utilizando-se o software Gauss.

Nota: Akaike $=-1.9886, \mathrm{~K}=2$.

Tabela 17 - Vetor cointegrante estimado por DOLS, Demanda por Energia Elétrica Comercial

\begin{tabular}{lcc}
\hline Variável & Coeficientes & Estatística - t \\
\hline & Vetor Cointegrante & \\
$\mathrm{C} 1$ & 5.2677 & 1.076645 \\
$\mathrm{Tc}$ & -0.9752 & -2.04188 \\
$\mathrm{Yc}$ & 1.1028 & 4.704778 \\
& Lead & \\
$\mathrm{Tc}(+1)$ & -0.4018 & -1.0198 \\
Yc $(+1)$ & 0.2677 & 0.678237 \\
& Lag & \\
Tc $(-1)$ & 0.0148 & 0.027888 \\
Yc $(-1)$ & -0.6656 & -1.9704 \\
\hline
\end{tabular}

Fonte: Resultados obtidos utilizando-se o software Gauss.

Nota: Akaike $=-2.2465, \mathrm{~K}=1$. 
Tabela 18 - Vetor cointegrante estimado por DOLS, demanda por energia elétrica industrial

\begin{tabular}{lcc}
\hline Variável & Coeficientes & Estatística - t \\
\hline & Vetor Cointegrante & \\
C1 & 8.0293 & 3.477845 \\
Ti & -3.7064 & -4.23589 \\
Yi & 1.2071 & 5.786673 \\
PEI & 0.965 & 2.574707 \\
PC & 0.5079 & 3.556723 \\
& Lead & \\
Ti (+1) & -0.6405 & -1.93271 \\
Yi (+1) & 0.4913 & 3.997559 \\
PEI (+1) & 0.3208 & 1.890395 \\
PC (+1) & 0.0986 & 1.550314 \\
Ti (+2) & -1.1704 & -2.24645 \\
Yi (+2) & 0.442 & 2.801014 \\
PEI (+2) & 0.4566 & 2.161932 \\
PC (+2) & 0.3487 & 2.696829 \\
& Lag & \\
Ti (-1) & 1.4822 & 4.877262 \\
Yi (-1) & -0.2646 & -1.29199 \\
PEI (-1) & 0.0268 & 0.160096 \\
PC (-1) & -0.0183 & -0.18466 \\
Ti (-2) & 0.7407 & 4.513711 \\
Yi (-2) & -0.2156 & -1.03754 \\
PEI (-2) & -0.1228 & -0.89898 \\
PC (-2) & 0.0765 & 0.992218 \\
\hline & & \\
\hline
\end{tabular}

Fonte: Resultados obtidos utilizando-se o software Gauss.

Nota: Akaike $=-1.9886, \mathrm{~K}=2$. 


\section{ANEXO III}

Tabela 19 - Previsão do consumo residencial, 2004-2010

\begin{tabular}{|c|c|c|c|c|c|c|}
\hline \multirow{3}{*}{ Ano } & \multicolumn{3}{|c|}{ DOLS } & \multicolumn{3}{|c|}{ Mudança de Regime } \\
\hline & Cenário A & Cenário $\mathrm{B}$ & Cenário C & Cenário A & Cenário B & Cenário C \\
\hline & $\begin{array}{c}\text { Consumo previsto } \\
\text { (TWh) }\end{array}$ & $\begin{array}{c}\text { Consumo previsto } \\
\text { (TWh) }\end{array}$ & $\begin{array}{c}\text { Consumo previsto } \\
\text { (TWh) }\end{array}$ & $\begin{array}{c}\text { Consumo previsto } \\
\text { (TWh) }\end{array}$ & $\begin{array}{c}\text { Consumo previsto } \\
\text { (TWh) }\end{array}$ & $\begin{array}{c}\text { Consumo previsto } \\
\text { (TWh) }\end{array}$ \\
\hline 2004 & 11.95 & 11.95 & 11.90 & 11.95 & 11.16 & 10.61 \\
\hline 2005 & 12.67 & 12.07 & 11.99 & 12.60 & 11.95 & 11.40 \\
\hline 2006 & 13.67 & 12.63 & 12.38 & 13.03 & 13.02 & 12.14 \\
\hline 2007 & 15.40 & 13.54 & 13.50 & 14.25 & 14.31 & 13.36 \\
\hline 2008 & 17.20 & 14.42 & 13.80 & 15.99 & 15.67 & 14.49 \\
\hline 2009 & 19.13 & 15.29 & 14.84 & 18.17 & 16.84 & 15.91 \\
\hline 2010 & 21.21 & 16.14 & 15.36 & 20.79 & 18.19 & 17.17 \\
\hline
\end{tabular}

Fonte: Resultados da pesquisa.

Tabela 20 - Previsão do consumo comercial, 2004-2010

\begin{tabular}{|c|c|c|c|c|c|c|}
\hline \multirow{3}{*}{ Ano } & \multicolumn{3}{|c|}{ DOLS } & \multicolumn{3}{|c|}{ Mudança de Regime } \\
\hline & Cenário A & Cenário $\mathrm{B}$ & Cenário C & Cenário A & Cenário $B$ & Cenário C \\
\hline & $\begin{array}{c}\text { Consumo previsto } \\
\text { (TWh) }\end{array}$ & $\begin{array}{c}\text { Consumo previsto } \\
\text { (TWh) }\end{array}$ & $\begin{array}{c}\text { Consumo previsto } \\
\text { (TWh) }\end{array}$ & $\begin{array}{c}\text { Consumo previsto } \\
\text { (TWh) }\end{array}$ & $\begin{array}{c}\text { Consumo previsto } \\
\text { (TWh) }\end{array}$ & $\begin{array}{c}\text { Consumo previsto } \\
\text { (TWh) }\end{array}$ \\
\hline 2004 & 6.36 & 6.28 & 5.91 & 6.47 & 6.35 & 5.91 \\
\hline 2005 & 6.68 & 6.60 & 6.20 & 6.79 & 6.66 & 6.20 \\
\hline 2006 & 7.01 & 6.93 & 6.51 & 7.13 & 7.00 & 6.51 \\
\hline 2007 & 7.37 & 7.27 & 6.84 & 7.49 & 7.35 & 6.84 \\
\hline 2008 & 7.73 & 7.64 & 7.18 & 7.86 & 7.72 & 7.18 \\
\hline 2009 & 8.12 & 8.02 & 7.54 & 8.25 & 8.10 & 7.54 \\
\hline 2010 & 8.53 & 8.42 & 7.91 & 8.67 & 8.51 & 7.91 \\
\hline
\end{tabular}

Fonte: Resultados da pesquisa.

Tabela 21 - Previsões do consumo industrial, 2004-2010

\begin{tabular}{lcccccccc}
\hline & \multicolumn{3}{c}{ DOLS } & & \multicolumn{3}{c}{ Mudança de Regime } \\
\cline { 2 - 4 } Ano & Cenário A & Cenário B & Cenário C & & Cenário A & Cenário B & Cenário C \\
\cline { 2 - 3 } & $\begin{array}{c}\text { Consumo previsto } \\
\text { (TWh) }\end{array}$ & $\begin{array}{c}\text { Consumo previsto } \\
\text { (TWh) }\end{array}$ & $\begin{array}{c}\text { Consumo previsto } \\
\text { (TWh) }\end{array}$ & $\begin{array}{c}\text { Consumo previsto } \\
\text { (TWh) }\end{array}$ & $\begin{array}{c}\text { Consumo previsto } \\
\text { (TWh) }\end{array}$ & $\begin{array}{c}\text { Consumo previsto } \\
\text { (TWh) }\end{array}$ \\
\hline 2004 & 25.50 & 24.51 & 23.93 & & 25.77 & 24.78 & 24.00 \\
2005 & 26.78 & 25.74 & 25.12 & & 27.06 & 26.01 & 25.20 \\
2006 & 28.12 & 27.03 & 26.38 & & 28.42 & 27.31 & 26.46 \\
2007 & 29.52 & 28.38 & 27.70 & & 29.84 & 28.67 & 27.79 \\
2008 & 30.99 & 29.80 & 29.10 & & 31.33 & 30.11 & 29.17 \\
2009 & 32.55 & 31.90 & 30.54 & & 32.90 & 31.61 & 30.63 \\
2010 & 34.18 & 32.85 & 32.07 & & 34.54 & 33.19 & 32.17 \\
\hline
\end{tabular}

Fonte: Resultados da pesquisa. 